NBER WORKING PAPER SERIES

FORECASTING THE COST OF U.S. HEALTH CARE IN 2040

\author{
Robert W. Fogel \\ Working Paper 14361 \\ http://www.nber.org/papers/w14361 \\ NATIONAL BUREAU OF ECONOMIC RESEARCH \\ 1050 Massachusetts Avenue \\ Cambridge, MA 02138 \\ September 2008
}

This work was supported in part by NIH program project grant number P01 AG10120. The views expressed herein are those of the author(s) and do not necessarily reflect the views of the National Bureau of Economic Research.

NBER working papers are circulated for discussion and comment purposes. They have not been peerreviewed or been subject to the review by the NBER Board of Directors that accompanies official NBER publications.

(C) 2008 by Robert W. Fogel. All rights reserved. Short sections of text, not to exceed two paragraphs, may be quoted without explicit permission provided that full credit, including $\odot$ notice, is given to the source. 
Forecasting the Cost of U.S. Health Care in 2040

Robert W. Fogel

NBER Working Paper No. 14361

September 2008

JEL No. I11

\begin{abstract}
$\underline{\text { ABSTRACT }}$
One of the most important debates among health economists in rich nations is whether advances in biotechnology will spare their health care systems from a financial crisis. We must consider that prevalence rates of chronic diseases declined during the twentieth century and that this rate of decline has accelerated. However, health care costs may continue to increase even as the age of onset of chronic diseases is delayed, because the proportion of a cohort living to late ages will increase. The accelerating decline in the prevalence of chronic diseases during the course of the twentieth century supports the proposition that increases in life expectancy during the twenty-first century will be fairly large, but the effect on health care in the U.S. will be modest. The income elasticity for health services is calculated at 1.6, meaning that income expenditures on health care in the U.S. are likely to rise from a current level of about 15 percent to about 29 percent of GDP in 2040.
\end{abstract}

\author{
Robert W. Fogel \\ Director, Center for Population Economics \\ University of Chicago, Graduate School of Business \\ 5807 S. Woodlawn Avenue, Suite 367 \\ Chicago, IL 60637 \\ and NBER \\ rwf@cpe.uchicago.edu
}




\section{Forecasting the Cost of U.S. Health Care in 2040}

In attempting to forecast the cost of health care a generation into the future, several different issues must be considered. The first of these is the likely downward trend in age-specific prevalence rates of chronic diseases and disabilities. Secondly, there is the rate of change in the cost of treating these conditions: will advances in biotechnology reduce or increase the cost of treatment? A third issue is the likely increase in the number and proportion of the population that is elderly. A fourth issue is the rate of growth of per capita income and the impact of economic growth on the demand for the quantity and quality of health care.

Each of these issues is so large and complex that it would take a book to address them properly. My aim in this paper is merely to outline the issues and to sketch some tentative answers.

\section{Trends in Prevalence Rates and the Cost of Health Care}

One of the most important debates among health economists and biomedical specialists in the United States and other rich (OECD) nations is whether rapid advances in biotechnology will spare their health systems from a financial crisis. This debate turns on four propositions.

First, there is now convincing evidence that prevalence rates of chronic diseases declined during the twentieth century. Second, the rate of decline in these prevalence rates has accelerated. In the American case, prevalence rates declined at a rate of about 1 percent per annum between 1910 and 1980. Between the early 1980 s and 1989, they declined at about 1.2 percent per annum. During the 1990s, the rate of decline further accelerated, reaching a level of about 2.0 percent per annum. Some investigators believe that a rate of decline in annual prevalence rates of 1.5 percent will be enough to offset the rising cost of health care, thus stabilizing the share of health care costs in GDP at its current 
level of about 15 percent.

Third, there is an unresolved issue regarding how much of the decline in the prevalence rates of OECD nations has been due to improvements in the environment and how much has been due to biomedical interventions. Partitioning the decline in prevalence rates into environmental effects and medical intervention effects is quite complex because of the long reach of nutritional and other biomedical insults at earlier ages on the odds of developing chronic diseases at middle and late ages. Although such life-cycle effects have long been suspected in particular diseases, only recently has a substantial body of evidence bearing on the interconnections been amassed. Longitudinal studies connecting chronic diseases at maturity, middle ages, and late ages to conditions in utero, infancy, and early childhood were reported with increasing frequency beginning in the 1980 s and extending through the end of the twentieth century. The exact mechanisms by which malnutrition and trauma at early ages affect waiting time to the onset of chronic diseases are still unclear, but it seems reasonable to infer that environmental insults during the period when cell growth is rapid could lead to long-lasting impairments of vital organs.

It is important to emphasize that medical interventions have not only contributed to the decline in prevalence rates of chronic conditions but also to the reduction in their severity. Advances in both surgical and drug therapies have significantly reduced the rate at which chronic conditions turn into disabilities that severely impair functioning. Such interventions have been especially effective in genitourinary, circulatory, digestive, and musculoskeletal conditions. However, many of the surgical procedures are quite expensive, and the cost of the new and more effective drugs is increasing sharply, mainly because of the large investments in developing these drugs.

Fourth, there is a debate over whether the mounting evidence of the long-term decline in the prevalence rate of chronic diseases means that the supply of treatable chronic diseases is declining. (The word supply here distinguishes the physiological burden of health care from the demand for health care 
services that may rise even if the physiological burden remains constant or declines.) Moreover, to address the question of whether declines in age-specific physiological prevalence rates will relieve current fiscal pressure on the health care systems of OECD nations, it is necessary to weight the existence of a particular chronic disease by the cost of treating that condition, which generally increases with age.

Figure 1

Relative Burden of Health Care by Age, U.S. Data circa 1996

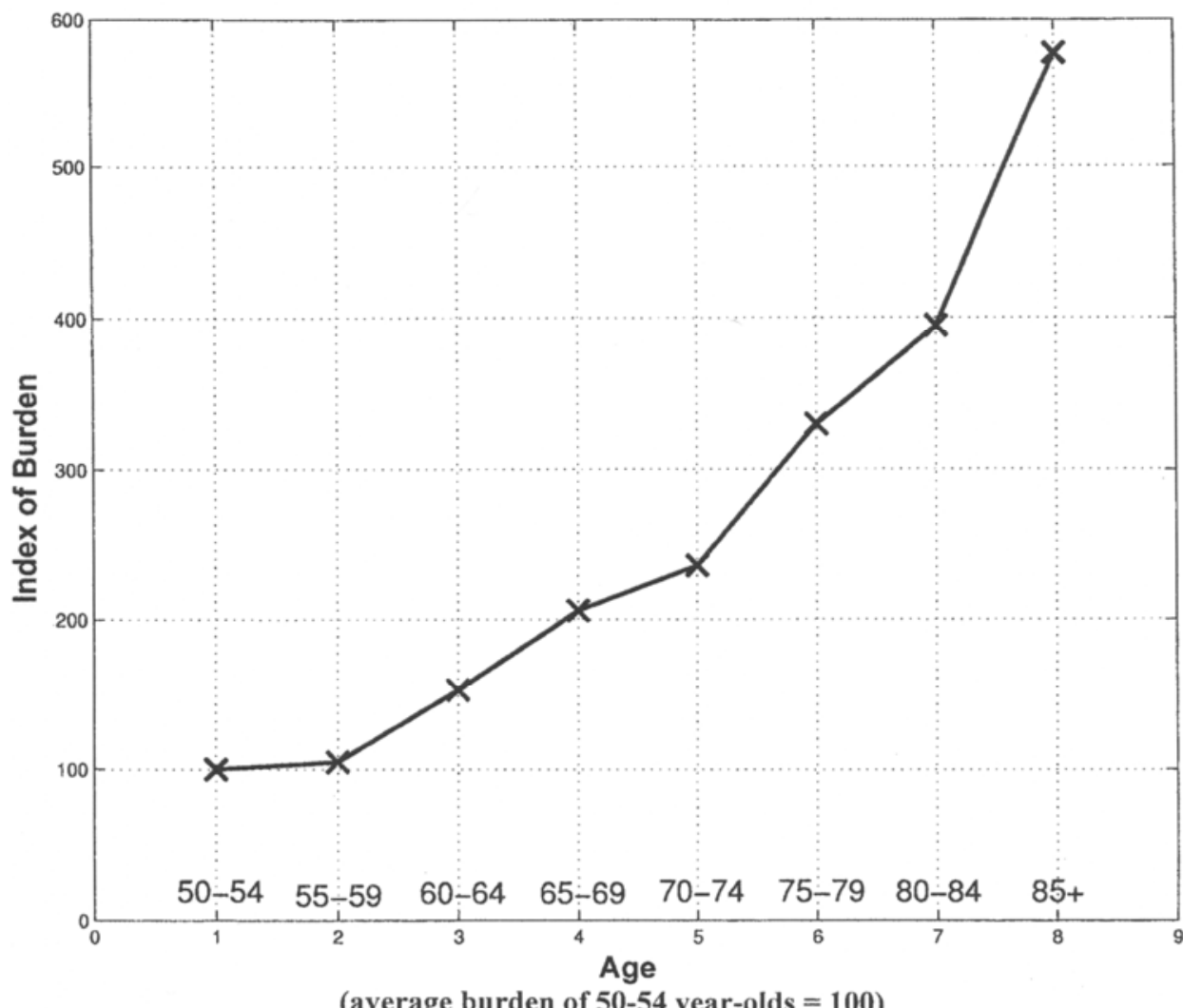

(average burden of $50-54$ year-olds $=100$ )

Source: Fogel 2004.

Such an index is shown in Figure 1. In this figure, the burden of per capita health care costs, which is based on U.S. data, is standardized at 100 for ages $50-54$. Figure 1 shows that the financial burden of health care per capita rises slowly in the 50s, accelerates in the 60 s, accelerates again in the 
70s, and accelerates even more rapidly after the mid-80s. The financial per capita burden at age 85 and older is nearly six times as high as the burden at ages 50-54. Notice that the financial burden of health care for ages 85 and older is over 75 percent higher per capita than at ages $75-79$. However, the physiological prevalence rates (number of conditions per person) is roughly constant at ages 80 and over.

Figure 2

How Will the Curve of Relative Disease Burden Shift?

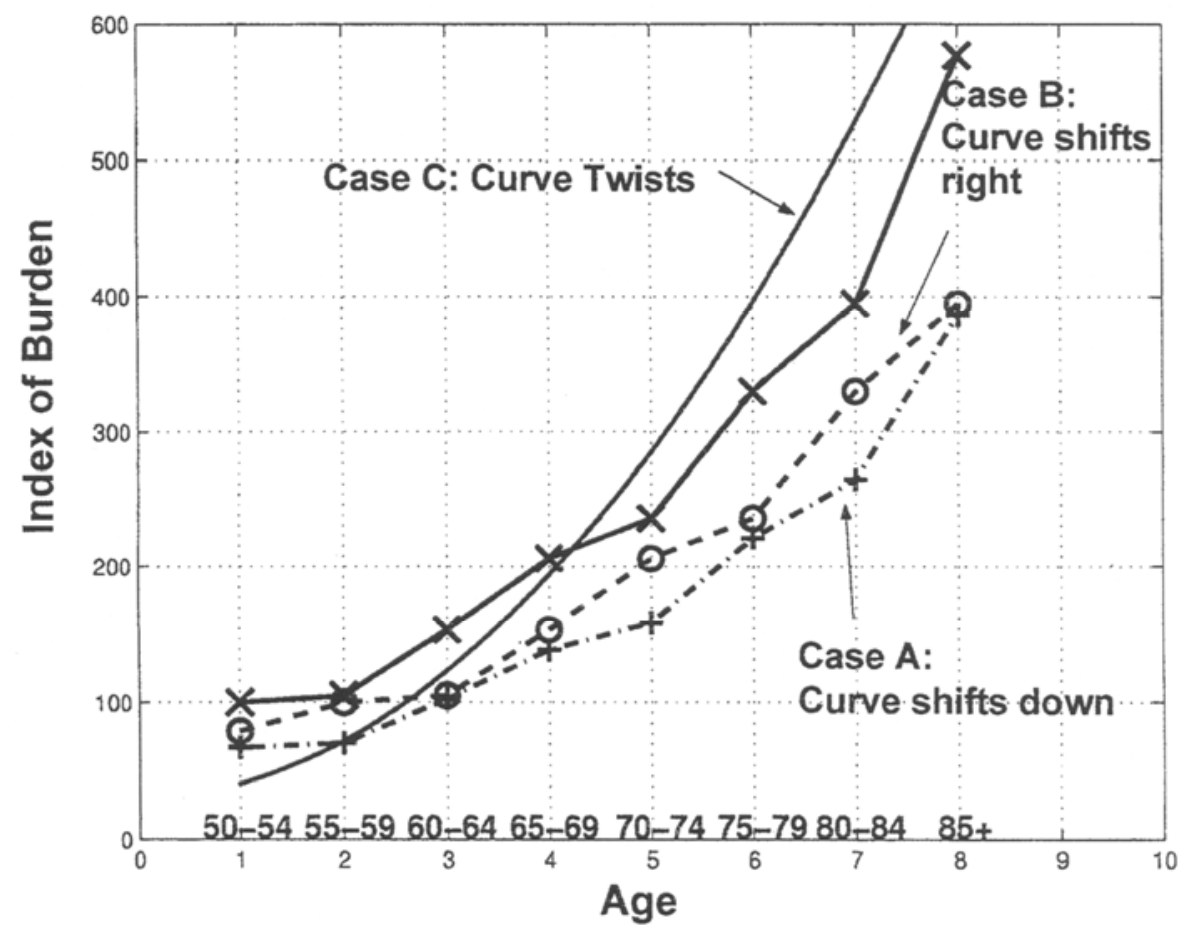

Source: Fogel 2004.

Costs rise, even though the number of conditions (comorbidities) per person remains constant, because the severity of the conditions increases or because the cost of preventing further deterioration (or even partially reversing deterioration) increases with age. It should be kept in mind that standard prevalence rates merely count the number of conditions, neglecting both the increasing physiological deterioration with age and the rising cost of treatment per condition. Figure 1 indicates that to forecast 
the future financial burden of health care, it is necessary to make use of a function of the age-specific cost of health care, such as that shown in Figure 1.

What, then, can be said about the likely movements in the curve of the relative burden of health care costs over the next generation? Figure 2 lays out three possibilities. The first possibility is that there will be a proportional downward shift in the curve (case A). This is the curve obtained by using the change in the average prevalence rates, which implies a shift downward at a constant average rate at all ages. The example shown in Figure 2 implies a decline in average prevalence rates of 1.2 percent per annum, which locates all of the points in case A at about two-thirds of the previous level. If 1.5 percent had been used, which is the high end of current forecasts of the decline in prevalence rates, the points on the case A curve would all be located at about 60 percent of the original level.

A second alternative, shown as case B in Figure 2, is that the curve of disease burden by age will shift to the right. The case B curve was constructed on the assumption that over the course of a generation, the average age of onset of chronic conditions is delayed by about five years. This assumption is supported by a number of epidemiological studies in the Netherlands, Britain, the United States, and elsewhere. This forecast is based partly on the evidence that the average age of the onset of chronic disabilities has been declining since the start of the twentieth century. It is also based on studies of the relative cost of health care by years before death. These studies have produced the curve shown in Figure 3, which is standardized on the average costs of health care for all persons age 65 and over in the U.S. Medicare program. Figure 3 shows that, five years before the year of death, annual health cost is virtually the same as all annual Medicare costs per capita. By the second year before death the cost has risen by about 60 percent, and in the year of death the annual cost exceeds the average by over four times. Indeed, expenditure on persons during their last two years of life account for 40 percent of all Medicare expenditures. 
Figure 3

Index of Average Annual Health Care by Year before Death

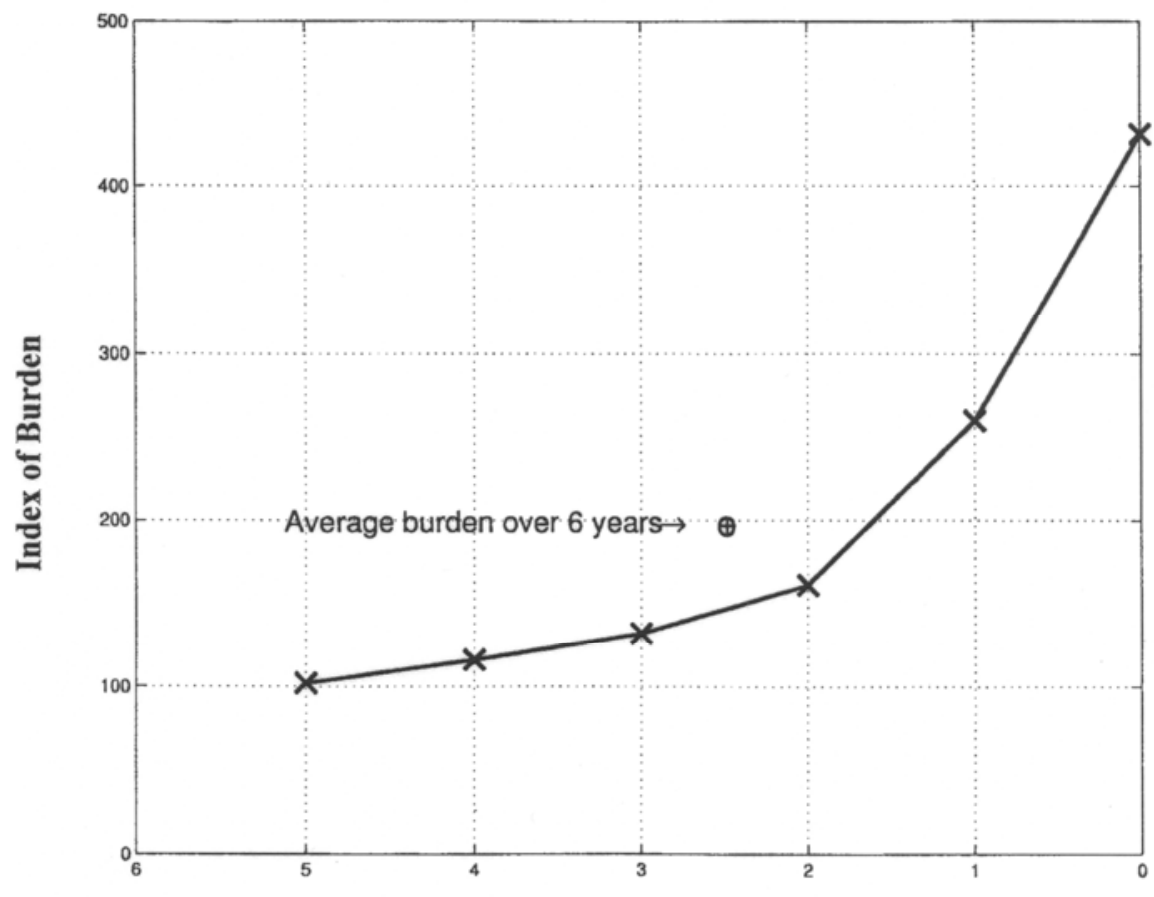

Calendar Years before Death

Source: Fogel 2004.

The pattern portrayed in Figure 3 has not changed significantly over the past two decades. The relative constancy in health care costs by years before death supports Case B in Figure 2 because it implies that no matter how far to the right the health care curve shifts, age-specific costs will eventually rise sharply as the proportion of persons who die in any given age category increases. This line of reasoning implies that health care costs may continue to increase even if the age of onset of chronic diseases is delayed, because the proportion of a cohort living to late ages will increase. Moreover, the cost of keeping disabilities under control may rise because more effective drugs and procedures may be more expensive than the current set. 


\section{Trends in Life Expectancy}

Will the twenty-first century witness as large an increase in the average life expectancy of the rich countries - thirty to forty years - as occurred during the twentieth century? Most experts believe it will not. The middle estimate of the U.S. Census Bureau, for example, is that the increase in life expectancy between 2000 and 2050 will be only about 7 years, and the estimated increase for the entire twenty-first century is just 13 years. This is less than half the increase that occurred during the twentieth century. The same conservatism is evident in the projections of the UN, OECD, and other national and international agencies (US Census Bureau 2000).

These pessimistic projections rest on several propositions. Perhaps the most widely accepted is the proposition that opportunities for large reductions in mortality rates are possible only when death rates under age 5 are very high. Proponents of this view argue, for example, that the sharp decline in U.S. mortality rates during the twentieth century was the result of a unique opportunity that cannot be replicated by those nations that have already experienced it: the opportunity to wipe out the majority of deaths due to acute infectious diseases, which were concentrated in infancy and early childhood. Whereas more than a third of all deaths at the turn of the twentieth century were of children under 5 , today infant and childhood deaths are less than 2 percent of the annual total. By contrast, deaths among persons age 65 and over, which accounted for just 18 percent of the total in 1900, have grown to three-quarters of all deaths today (US National Center for Health Statistics 1997; Preston, Keyfitz, and Schoen 1972; Preston 1985; Linder and Grove 1947). Thus, at the start of the twenty-first century, the argument goes, the more than 90 percent of birth cohorts who live to age 50 begin to suffer from an increasing number of chronic diseases because their vital organ systems naturally lose their effectiveness with aging, and this deterioration eventually increases to a point where life can no longer be sustained. 
Empirical observations are buttressed by a variety of theories, some of them drawn from evolutionary biology, as to why the cells of vital organ systems decay. One prominent theory holds that because reproduction ceases at age 50 , there is a sharp rise in deaths at post reproductive ages because the forces of natural selection have not eliminated the genes that hasten rapid physiological decline past age 50. There are, however, persuasive arguments that spell out a more optimistic view of the course of changes in health and longevity during the twenty-first century. One of these arguments is based on the projection not of past changes in average life expectancy but of record life expectancy since 1840. Record life expectancy is defined as the highest life expectancy experienced by any country at each point in time. For example, the record life expectancy at birth in 1840 was found among Swedish women, who lived on average a bit over 45 years. In the year 2000, Japanese women achieved a record life expectancy of nearly 85 years. Fitting a curve to such best practice observations over a period of 160 years yields a linear curve, which suggests that for the foreseeable future, female life expectancy will increase at 2.4 years per decade and male life expectancy will increase at 2.2 years per decade. These equations lead to the prediction that by 2070 female life expectancy in the United States will be between 92.5 and 101.5 years, which substantially exceeds the forecast of 83.9 years made by the Social Security Administration in 1999 (Oeppen and Vaupel 2002).

The fact is that demographers' past predictions of maximum life expectancy have been notoriously conservative when these forecasts were based on average experience. In the late 1920s, L. I. Dublin, the chief actuary of the Metropolitan Life Insurance Company, put a cap of 64.75 years on life expectancy for both men and women. In 1936, he collaborated with the leading mathematical demographer of the first half of the twentieth century to publish a revised upper limit of 69.93 years (Dublin 1928; Dublin and Lotka 1936). More recently, a leading gerontologist set an upper limit on life (excluding some major breakthrough in molecular biology) of 85 plus or minus 7 years (Fries 1980, 
1990). Generally speaking, these caps tend to be in the range of 5 to 10 years beyond the observed life expectancy at the time the forecasts were published (Oeppen and Vaupel 2002 suppl).

The accelerating decline in the prevalence of chronic diseases during the course of the twentieth century supports the proposition that increases in life expectancy during the twenty-first century will be fairly large. At the beginning of the twentieth century, the burden of chronic diseases among elderly Americans was not only more severe but began more than 10 years earlier in the life cycle than it does today. Moreover, the number of comorbidities at each age between 50 and 70 is well below levels that prevailed a century ago. This is, according to one study, equivalent to pushing back old age, since an increase of one unit in a comorbidity index is the equivalent of being a decade older. Studies of changes in functional limitations among persons who have reached age 65 since the early 1980 s indicate that such limitations declined at an accelerating rate during the balance of the $1980 \mathrm{~s}$ and the $1990 \mathrm{~s}$ (Helmchen 2003; Charlson et al. 1994; Stuck et al. 1999; Manton and Gu 2001).

Dora Costa has found that favorable changes in body size, particularly the decline in the waistto-hip ratio (a measure of abdominal fat), explained close to half of the decline in mortality rates above age 65 during the course of the twentieth century (Costa 2004). Taking account of the characteristics of men of military age in 1988, she predicts that the annual decline in male mortality rates after age 65 will be nearly twice as high between 1988 and 2022 as it was between 1914 and 1988. Overall, the work on trends in chronic diseases and on frame sizes tends to support forecasts of continued linear trends in the extension of longevity during the twenty-first century.

\section{Changes in the Age Structure of the U.S. Population}

The increase in life expectancy coupled with stability in the fertility rate will lead to an increase in the share of the population over age 65 . Since the per capita consumption of health care services rises 
with age, the aging of the U.S. population would by itself lead to an increase in the burden of health care. However, as Table 1 shows, the effect will be modest. The change in the age structure of the population will raise annual per capita consumption from $\$ 3,819$ in 1999 to $\$ 4,443$ in 2040 , is a rise of just 16 percent in 41 years, or an annual rate of growth of 0.4 percent.

Table 1

The Effect of Changes in the Age Structure of the Population on the Per Capita Cost of Health Services, 1999-2040

\begin{tabular}{|c|c|c|c|c|c|}
\hline & $\begin{array}{c}\text { Per capita } \\
\text { consumption of } \\
\text { health services } \\
\text { (1) }\end{array}$ & $\begin{array}{c}\text { Age } \\
\text { distribution } \\
\text { in } 1999 \\
\text { (2) }\end{array}$ & $\begin{array}{c}\text { Col } 1 \\
\times \text { Col } 2 \\
(3)\end{array}$ & $\begin{array}{c}\text { Age } \\
\text { distribution } \\
\text { in } 2040 \\
\text { (4) }\end{array}$ & $\begin{array}{r}\text { Col } 1 \\
\times \text { Col } 4 \\
(5)\end{array}$ \\
\hline $0-18$ & 1,872 & .2865 & 536 & .2408 & 451 \\
\hline $19-64$ & 3,230 & .5878 & 1,899 & .5615 & 1,814 \\
\hline $65+$ & 11,018 & .1256 & 1,374 & 1977 & 2,178 \\
\hline $\begin{array}{l}\text { Per capita } \\
\text { over all ages }\end{array}$ & & & 3,819 & & 4,443 \\
\hline
\end{tabular}

Sources: Col 1, Hartman et al. 2007; Cols 2and 4, Population Projection Program, Population Division, U.S. Census Bureau (http://www.census.gov/population/www/projections/index.html).

However, the demand for health care will grow much more rapidly than indicated by Table 1. Hence, changes in the age structure are a minor factor in the expected rise in the burden of health services over the next several decades. The main factor is the increase in the demand for health care.

\section{Explaining the Growth in the Demand for Health Care}

The principal factor driving the growth in expenditures on health care is demand. As people get richer, they want to spend a larger share of their income on improving their health. The fact is that the structure of consumption has changed drastically in the U.S. since the late nineteenth century and the 
growth in demand for health care has to be evaluated in that context.

Table 2 presents the change in the structure of consumption in the United States between 1875 and 1995. The trend in the structure of consumption in other OECD nations has been quite similar. The term "expanded consumption" takes account of the fact that as income has increased, consumers have preferred to take an increasing share of their real income in the form of leisure rather than in purchasing more commodities, as would be possible if they did not reduce their hours of work.

One notable feature of Table 2 is the change in the share of income spent on food, clothing, and shelter, which has declined from 74 percent of expanded consumption to just 13 percent over the 120year period. Another striking change is the share of income spent on health care, which has increased nine-fold, from 1 percent of expenditures to 9 percent.

Table 2

The Long-Term Trend in the Structure of Consumption and the Implied Income Elasticities of Several Consumption Categories

\begin{tabular}{lrrr} 
& \multicolumn{2}{c}{$\begin{array}{c}\text { Distribution of } \\
\text { Consumption (\%) }\end{array}$} & \\
\cline { 2 - 3 } $\begin{array}{l}\text { Consumption } \\
\text { Class }\end{array}$ & 1875 & 1995 & $\begin{array}{c}\text { Long-Term } \\
\text { Income } \\
\text { Elasticities }\end{array}$ \\
\hline Food & 49 & 5 & 0.2 \\
Clothing & 12 & 2 & 0.3 \\
Shelter & 13 & 6 & 0.7 \\
Health care & 1 & 9 & 1.6 \\
Education & 1 & 5 & 1.5 \\
Other & 6 & 7 & 1.1 \\
Leisure & 18 & 68 & 1.5 \\
\hline
\end{tabular}

Source: Fogel 2000. 
For purposes of forecasting, the most important feature of Table 2 is the last column, which presents the long-term income elasticities for each category of expenditures. The "income elasticity" is defined as the percentage increase in expenditures on a given commodity that will occur with a 1 percent increase in income. Notice that the income elasticities for food and clothing are quite low, which means that the share of these items in total consumption will continue to decline. An income elasticity of 1 means that the share of a given item in total consumption will remain constant. Notice that shelter, which includes most consumer durables, is closer to but still below 1 . On the other hand, the income elasticities for health care, education, and leisure are all well above 1 . The income elasticity of 1.6 means that income expenditures on health care in the United States are likely to rise from a current level of about 15 percent of GDP to about 29 percent of GDP in 2040 (Fogel 2007).

Is that bad? Should such a development be avoided? Should governments seek to thwart consumer demand for health care services? Such a policy would be necessary only if OECD nations lacked the resources to provide that much health care. However, the growth in productivity of traditional commodities, including food, clothing, shelter, and consumer durables will release the resources required to provide expanded health care. In the United States a century ago, it took about 1,700 hours of work to purchase the annual food supply for a family. Today it requires just 260 hours. If agricultural productivity grows at just two-thirds of its recent rates, then by 2040 a family's annual food supply may be purchased with about 160 hours of labor.

A recent study of the role of the change in the benefits and costs of health care conducted by investigators at the National Bureau of Economic Research (NBER) concluded that the benefits of health care services over the past 40 years have more than justified their costs. This analysis suggests a fundamental repositioning of the public debate about medical care from how governments can limit spending to how to get the most out of the spending that is undertaken. Other NBER investigators have also suggested changing the methods of health care financing so that the consumer demand for 
increasingly effective services is not unnecessarily thwarted.

Public policy should not be aimed at suppressing the demand for health care. Expenditures on health care are driven by demand, which is spurred by income and by advances in biotechnology that make health interventions increasingly effective. Just as electricity and manufacturing were the industries that stimulated the growth of the rest of the economy at the beginning of the twentieth century, health care is the growth industry of the twenty-first century. It is a leading sector, which means that expenditures on health care will pull forward a wide array of other industries including manufacturing, education, financial services, communications, and construction.

The pressure to suppress health care expenditures arises from the way that governments and businesses currently provide insurance in OECD countries. These institutions need to provide a basic and affordable package of health services. Beyond that, they should offer additional policies at higher costs that provide upscale services (such as private rooms, the most expensive alternative procedures and medicines, the shortest waiting time, the fullest coverage of optional services, and access to physicians anywhere in the country, not just in local clinics). Health care is not a homogeneous good, all of which is essential. There are large luxury components in health services that may appeal to some tastes but that are not necessary for sound basic health care. It is, of course, necessary to provide medical care for those who are too poor to purchase it from their own resources, but for those with more resources, shifting to private savings accounts for health services is an effective way to relieve pressure on the finances of both businesses and government. 


\section{References}

Charlson M, Szatrowski TP, Peterson J, Gold J. 1994. Validation of a combined comorbidity index. Journal of Clinical Epidemiology 47: 1245-1251.

Costa D. 2004. The measure of man and older age mortality: Evidence from the Gould Sample. Journal of Economic History 64: 1-23.

Dublin LI. 1928. Health and Wealth: A Survey of the Economics of World Health. New York and London: Harper and Brothers.

Dublin LI, Lotka AJ. 1936. Length of Life: A Study of the Life Table. New York: Ronald Press.

Fogel RW. 2000. The Fourth Great Awakening and the Future of Egalitarianism. Chicago: University of Chicago Press.

Fogel RW. 2003. Forecasting the demand for health care in OECD nations and China. Contemporary Economic Policy 21 ( 1): 1-10.

Fogel RW. 2004. The Escape from Hunger and Premature Death, 1700-2100: Europe, America, and the Third World. Cambridge: Cambridge University Press.

Fogel RW. 2007. Capitalism and democracy in 2040: Forecasts and speculations. NBER Working Paper 13184.

Fries JF. 1980. Ageing, natural death, and the compression of morbidity. New England Journal of Medicine 303: 130-136.

Fries JF. 1990. The sunny side of aging. Journal of the American Medical Association 263: 2354-2355.

Hartman M, Catlin A, Lassman D, Cylus J, Heffler S. 2007. U.S. Health Spending By Age, Selected Years through 2004. Health Affairs, January/February 2008: 27(1): w1-w12.

Helmchen L. 2003. Changes in the age at onset of chronic disease among elderly Americans, 1870-2000. Typescript: Center for Population Economics, University of Chicago.

Linder FE, Grove RD. 1947. Vital Statistics Rates in the United States 1900-1940. U.S. Government Printing Office: Washington, DC.

Manton KG, Gu X. 2001. Changes in the prevalence of chronic disability in the United States black and nonblack population above age 65 from 1982 to 1999. Proceedings of the National Academy of Sciences, USA 98: 6354-6359.

Oeppen J, Vaupel J. 2002. Broken limits to life expectancy. Science 296: 1029-1031. 
Oeppen J, Vaupel J. 2002 suppl. Broken limits to life expectancy, supplementary material. Available on the Internet at http://www.sciencemag.org/cgi/content/full/296/5570/1029/DC1 (last accessed 6

August 2008).

Preston SH. 1985. Resources, knowledge, and child mortality: A comparison of the U.S. in the late nineteenth century and developing countries today. In International Property Conference, Florence, 5-12 June, vol. 2, 373-386. Liège, Belgium: International Union for the Scientific Study of Population.

Preston SH, Keyfitz N, Schoen R. 1972. Causes of Death: Life Tables for National Populations. New York: Seminar Press.

Stuck AE, Walthert JM, Nikolaus T, Bula CJ, Hohmann C, Beck JC. 1999. Risk factors for functional status decline in community-living elderly people: A systematic literature review. Social Science and Medicine 48: 445-469.

US Census Bureau. 2000. Table C: Projected life expectancy at birth by race and Hispanic origin, 1999 to 2100. Available on the Internet at http://www.census.gov/population/www/documentation/ twps0038/tabC.txt (last accessed 6 August 2008).

US National Center for Health Statistics. 1997. Monthly Vital Statistics Report 46(1) suppl. (11 September). 